\title{
Determinants of General and Specified Resilience to Extreme Temperatures $\mathscr{O}$
}

\author{
ANA RAQUEL NUNES \\ Warwick Medical School, University of Warwick, Coventry, United Kingdom
}

(Manuscript received 28 June 2019, in final form 5 August 2020)

\begin{abstract}
Extreme temperatures impact human health and well-being. Yet, very little empirical evidence exists on what determines human resilience, both in general and in relation to specified extreme temperatures. This paper addresses this serious gap in knowledge by developing a quantitative measure of general resilience (i.e., the resilience of individuals to all daily life circumstances). This is complemented with qualitative elicitations of specified resilience (i.e., the resilience of individuals to a particular type of threat, stress, or event), which in this study are extreme heat and extreme cold. This research uses the "sense of coherence" (SOC) approach (i.e., Orientation to Life Questionnaire-SOC-13 scale) to develop a general resilience index (GRI) using a composite index approach and to develop assessments of heat-related resilience (HRR) and cold-related resilience (CRR) using primary data from mixed-method interviews with 52 older people living in Lisbon, Portugal. The findings show that most participants exhibited high levels of general resilience but low levels of specified resilience. In particular, resilience to cold was lower than resilience to heat. Sources of general and specified resilience were found to be dependent on cognitive, behavioral, and motivational factors in older people's lives. The findings reveal that believing threats (e.g., extreme temperatures) are structured and ordered, perceiving that assets are available to respond to them, and feeling it is worth responding are sources of resilience. Concrete policy recommendations can be generated from this study by both central and local governments to strengthen resilience. These can take the form of programs, plans, and actions that support individuals and enable them to better deal with challenging life events such as extreme temperatures and to improve both general and specified resilience.
\end{abstract}

KEYWORDS: Social Science; Europe; Emergency preparedness; Heat islands; Planning; Policy

\section{Introduction}

The frequency and intensity of extreme temperature events are increasing, imposing greater impacts on human health and well-being over time (IPCC 2018). As a result, in recent years the impact of temperature extremes have been receiving increased attention, as heat waves and cold waves result in deaths and changes in the patterns of morbidity (Nunes 2019a; Arbuthnott and Hajat 2017; Hajat 2017; Nogueira et al. 2009). This is particularly evident in some groups in society that are most vulnerable such as those living with low income, people with chronic diseases, pregnant women, children, and older adults (Committee on Climate Change 2014). Demographic changes such as an aging population are likely to increase the exposure and impacts of extreme temperatures on older adults (Royal Society 2014). Despite this, it is important to acknowledge that the older adult population does not constitute a homogeneous social group, and a range of factors contribute to possible impacts (Arbuthnott and Hajat 2017; Hajat 2017; Hales et al. 2012; Wolf et al. 2010).

The resilience of individuals and societies is modified by extreme temperatures (IPCC 2012). As a result, the IPCC $(2012,2018)$ has called for increased resilience of individuals as a way of reducing the impacts of extreme temperatures

Supplemental information related to this paper is available at the Journals Online website: https://doi.org/10.1175/WCAS-D-190078.s1.

Corresponding author: Ana Raquel Nunes, raquel.nunes@ warwick.ac.uk through improvements in planning and policy for strengthening resilience and enhancing adaptation in the short, medium, and longer terms.

As a result, calls for a better understanding of the factors and processes contributing to human resilience, as well as policies to improve resilience to extreme temperatures have been made (Hatvani-Kovacs et al. 2018). Research has shown that there is a narrative of resilience to heat waves among older people that is only altered due to negative changes in health status (e.g., illness, lack of mobility) (Wolf et al. 2010). Additionally, older people's life experiences are said to play an important role in their resilience to heat waves (Hansen et al. 2011). Regarding climate change, some international studies suggest that access to and availability of assets play a determinant role in the resilience of individuals in adapting to climate change (Nunes 2018; Royal Society 2014; Haq et al. 2008). For example, having physical (e.g., housing) and financial (e.g., income) as well as social assets (e.g., social contacts and networks), place-based assets (e.g., transport), and human assets (e.g., knowledge) contributes to the resilience of older people in adapting to climate change (Nunes 2019b, 2018; Haq et al. 2008).

Despite this, and as a result of lack of evidence on human resilience to climate change in general and extreme temperatures in particular, the IPCC has concluded that "research is needed on resilience of human populations to extreme events (factors that increase resilience), including responses [...]. Research is also needed on how adaptation policies may increase or reduce social inequalities" (Kovats et al. 2014, p. 1306). Moreover, it is acknowledged that a comprehensive approach is needed to address resilience in relation to issues 
such as inequalities and fuel poverty (Hales et al. 2012). Improving the resilience of most vulnerable individuals such as older people has also been advocated (Hales et al. 2012).

In summary, the lack of evidence on the determinants of human resilience to extreme temperatures is considered a major gap in knowledge (Hatvani-Kovacs et al. 2018; Cai et al. 2018; Clare et al. 2017). The aim of this paper is to investigate the general and specified resilience of individuals to extreme heat and cold temperatures.

\section{General and specified resilience}

Definitions of resilience vary according to focus (system, individual) and scale (temporal and spatial). The ecology, climate change, and disaster fields are more prone to consider a temporal scale (present; future) (e.g., Nelson et al. 2007) and to consider resilience to external events (e.g., Adger 2000). In the climate change literature, resilience is system oriented (Nelson et al. 2007), whereas the psychology and public health fields are generally interested in internal (individual) responses to either internal or external events (e.g., Bartley 2006; Almedom and Tumwine 2008).

Individual resilience is seen as a "dynamic process wherein individuals display positive adaptation despite experiences of significant adversity or trauma" (Luthar et al. 2000, p. 543). This has been found to be associated with characteristics of individuals and the places they live, which can include skills, education, and access to and quality of public amenities that are considered to influence the impacts of threats and stressors (Brown and Westaway 2011).

All of the various meanings suggest that resilience is considered to be mainly an ability, capacity, characteristic, or process a system uses to positively respond or adapt to threats, stresses, or events. As such, resilience exists in every system and is put to test in certain circumstances (e.g., disaster, shock). Additionally, according to Dominelli (2013) "resilience has nonlinear and fractured characteristics that can result in a system becoming resilient along one dimension, but not in another. And resilience can vary over time as the context changes" (Dominelli 2013, p. 208). This is a significant development in how resilience can be conceptualized and consequently assessed. The answer to the question "resilience to what?" is thus one that according to Folke et al. (2010) allows the distinction between general resilience (e.g., to a wide range of disturbances, shocks, or threats) and specified resilience (e.g., to individual disturbances, shocks, or threats). As a result, these authors define general resilience and specified resilience, respectively as "the resilience of any and all parts of a system to all kinds of shocks, including novel ones" (Folke et al. 2010, p. 3), and "the resilience "of what, to what'; resilience of some particular part of a system, related to a particular control variable, to one or more identified kinds of shocks" (Folke et al. 2010, p. 3). The Royal Society (2014) has also conceptualized resilience as general resilience and specific resilience, following Folke et al. (2010) definitions. Others have defined general resilience as "to how individuals respond to a range of shocks, rather than individual ones, hence general rather than specific resilience" (Waters and Adger 2017, p. 43).

Disciplinary boundaries have resulted in different conceptualizations of resilience with few attempts to provide interdisciplinary insights on how human resilience is shaped (Smith et al. 2014) that correspond to a great opportunity for improving current knowledge, which this research embraces.

As a result, several authors have made the case for assessing general and specified resilience (Waters and Adger 2017; Berkes and Ross 2013; Folke et al. 2010). The approach taken here is one that considers general and specified resilience to be related but independent, thus they need to be conceptualized and assessed separately.

In this paper, resilience is defined as the ability or capacity of individuals to respond to challenging life events or threats through actively accessing, mobilizing, and using the available assets to positively adapt. It is a function of 1) the ability to make sense of threats, 2) the availability and access to assets, and 3 ) the motivation to respond to threats. General resilience is defined as the resilience of individuals to all daily life circumstances, and specified resilience is defined as the resilience of individuals to a particular type of threat, stress, or event, which in the case of this study are extreme temperatures. In other words, general resilience represents the capacity or ability of individuals to manage life as a whole, whereas resilience to extreme temperatures is about the ability to make sense and manage the threat extreme temperatures pose, assess their assets portfolio, and be motivated in order to be able to respond to these threats.

To understand how to better protect older adults from the impacts of extreme temperatures, this paper aims to respond to the complex interactions between extreme temperatures, resilience, health, and well-being and provides an interdisciplinary and holistic approach to explore and understand the multiple factors/assets (e.g., human, financial, physical, place based, social) that shape general and specified resilience and contribute to positive outcomes, using an asset-based approach. This paper makes contributions to theory, policy, and practice. It offers a conceptual and analytical framework for understanding general and specified resilience, as well as a range of opportunities for reducing the impacts of extreme temperatures through a focus on improving resilience.

\section{Resilience assessments}

As a result of the diverse disciplinary roots of the concept of resilience a variety of tools and measures to assess resilience have been developed (e.g., Cai et al. 2018; Leichenko 2011; Martin-Breen and Anderies 2011). In the field of health, this has led to many ways of assessing resilience, with no agreement on which approach or indicators to use (Castleden et al. 2011). Following these concerns, Engle et al. (2013) acknowledge the challenges and difficulties in achieving a set of appropriate indicators for assessing resilience. Despite a quantitative approach being considered as most desirable for policy makers, a qualitative approach on resilience is considered to be an alternative to overcome the challenges for compiling resilience indicators and can even be a more suitable way of measuring resilience through the implementation of case studies (Engle et al. 2013).

A systematic review of the literature on resilience definitions and assessments in the fields of public health and psychology highlights the successful use of "sense of coherence" (SOC) 
scale as a quantitative measurement for individual resilience (Almedom and Glandon 2007). Since then, the SOC scale has been used to measure individual resilience to, for example, war in Eritrea (Almedom et al. 2007), Hurricane Katrina (Glandon et al. 2008), and the Second Lebanon War (Kimhi et al. 2010). In addition, the use of the SOC scale to assess human resilience is gaining more interest from researchers and is considered to be an accepted tool to assess individual resilience (Kimhi 2016).

The SOC approach to resilience is grounded in the theory of salutogenesis, the study of the origins of health focusing on the resources or assets and strategies that support individuals in coping with and adapting to life situations (Antonovsky 1979, 1987, 1993). Antonovsky (1979, p. 19) defined the SOC as

a global orientation that expresses the extent to which one has a pervasive, enduring though dynamic feeling of confidence that 1) the stimuli deriving from one's internal and external environments in the course of living are structured, predictable, and explicable; 2) the resources are available to one to meet the demands posed by these stimuli; and 3) these demands are challenges, worthy of investment and engagement.

The three components presented above are called comprehensibility, manageability, and meaningfulness, respectively (Antonovsky 1993). First, the comprehensibility component refers to the cognitive dimension defined as the skill to make sense, assess order and structure, and understand the stressor. Second, the manageability component represents the instrumental or behavioral dimension and is defined as the perception of availability of assets to face the threat and the power to do so. Third, the meaningfulness component refers to the motivational dimension and expresses the degree of incentive and aspiration to deal with the stressor. Hence, the components reflect cognitions, capacities, and motivations, respectively (Almedom 2005; Lindstrom and Eriksson 2005, 2006; Lezwijn et al. 2011).

Within the SOC approach individuals mobilize generalized resistance resources (GRRs) (i.e., assets) to cope with stresses and threats (Almedom 2005), which indicates a relationship between individuals and their environment (Eriksson and Lindstrom 2008). The SOC approach can help in explaining human adaptation and response to stressors for the mobilization of assets or GRRs (Almedom et al. 2007). These are available to an individual or community to facilitate the process of coping effectively and can be grouped as human (e.g., level of education, knowledge, health, and life experiences), financial (e.g., income and savings), physical (e.g., type of housing and housing tenure), place based (e.g., local infrastructure, amenities, and services), and social (e.g., social networks and social support). Almedom's (2009) work on human resilience advanced the view that "individuals, families, and communities that can generate and access social capital and the material resources needed to maintain health and social stability are likely to build resilience" (Almedom 2009, p. 3). According to Antonovsky (1996, p. 15) an individual with a strong SOC facing an adversity or threat will "wish to, be motivated to, cope (meaningfulness); believe that the challenge is understood (comprehensibility); believe that resources to cope are available (manageability)."
Since Antonovsky and his research with survivors of the Holocaust (Antonovsky 1979), the SOC scale has been used in more than 458 academic papers and more than 33 languages (Eriksson and Lindstrom 2005). It has been implemented in different age samples, including older people with good reliability and validity (e.g., Forbes 2001; Schneider et al. 2004; Borglin et al. 2006; Drageset et al. 2008; Wiesmann and Hannich 2010; Naaldenberg et al. 2011). The SOC is considered to be a universally meaningful construct that cuts across sex, social class, region, and culture differences; in addition, it does not relate to a particular type of coping strategy but to factors allowing specific coping with stresses (Antonovsky 1993). More recently, Griffiths et al. (2011) using a qualitative approach to the SOC through thematic analysis have found that the SOC should be applied both to life overall and also to specific events.

As "the paradigm of social resilience is a way of understanding processes of change in terms of meaning (coping capacity) and even frame them (adaptive and participative capacity)" (Lorenz 2013, p. 19), similarly, the SOC defines perceptions of the environment based on comprehensibility, manageability, and meaningfulness (Antonovsky 1993; Eriksson and Lindstrom 2008), thus reflecting the synergy between the individual and the environment. This is to say that in line with resilience, the SOC reflects an individual's ability to respond to stresses (Eriksson and Lindstrom 2005), and highlights the means by which individuals use the assets available to preserve their health (Lezwijn et al. 2011).

The SOC has been used to quantitatively measure resilience and accompanied with qualitative assessments (Almedom et al. 2007; Glandon et al. 2008). It is used in this paper to better understand general and specified resilience to extreme temperatures through the development of a general resilience index (GRI) and assess specified resilience to extreme temperatures [heat-related resilience (HRR) and cold-related resilience (CRR)] (see methods section).

This paper aims to develop a coherent and comprehensive conceptual, as well as empirical account for understanding general and specified resilience (i.e., to extreme temperatures). In doing this, it seeks to provide a complete account of how to support actions to move forward on ways to increase resilience, as well as tools to help strengthening its implementation. This research is novel because of its 1) conceptual novelty-it reinterprets conceptual findings to assess general and specified resilience, 2) empirical novelty-it develops a quantitative measure of general resilience and qualitative assessments of specified resilience for improving the understanding of the factors that influence resilience, and 3) practical novelty-it provides an improved, more coherent account of what a resilient individual looks like. This research has the potential to inform, provide evidence, and influence government, academia, the third sector (i.e., nongovernmental organizations), and the wider public in exploring alternative ways of improving general and specified resilience to extreme temperatures.

\section{Methods}

\section{a. Study area}

This research was implemented in Portugal, a country that is vulnerable to extreme temperatures with significant impacts on human health (Carvalho et al. 2014; Lucio et al. 2010). It focuses 
on the city of Lisbon, Portugal's capital, because of high mortality and morbidity rates associated with extreme temperatures, with older people being the most affected group (Almeida et al. 2010; Hajat et al. 2007; Basu 2009). Despite its mild Mediterranean climate, Lisbon has been faced with increasingly frequent and intense heat waves (i.e., 1981, 2003, 2006, 2010, and 2018) and cold waves (i.e., 2003, 2010, 2012, and 2018).

\section{b. Research design and data}

This study uses an interseasonal mixed-methods approach combining structured and semistructured interviews. Data were collected during summer months for phases 1 and 2 (general and heat-related resilience, respectively) and during winter months for phase 3 (cold-related resilience).

Local authorities and public or charitable institutions working with older people were approached to gain access to participants. Those who expressed an interest were asked if they were willing to participate and contacted at a later stage to arrange an interview. Participants were selected according to the following inclusion criteria: being 65 years of age or over, living independently in their homes, and living in the city of Lisbon. A mix of nonprobability sampling techniques was used to ensure participants with diverse characteristics (e.g., age, sex, marital status, living arrangements, education level, financial status, and health status). Only participants with sufficient competence and autonomy to understand the study and their involvement were included. Face-to-face interviews were arranged to take place in a familiar location to participants, in a private and neutral environment and were digitally recorded. Ethical approval was obtained from the University of East Anglia Faculty of Medicine and Health Sciences Research Ethics Committee (Reference 2011/12-30) and from Universidade de Lisboa, Instituto de Ciências Sociais Ethical Committee. Written informed consent was obtained for a total of 52 participants.

Quantitative data collection (phase 1) included sociodemographic characteristics, and the SOC scale (SOC-13) to assess general resilience. Qualitative data collection (phases 2 and 3) comprised participants' characteristics of specified resilience (heat and cold related). Phases 1 and 2 interviews were implemented concurrently during summer months and phase 3 interviews were implemented during winter months. The decision to do this was one of timing and the objective was to get to know participants' general resilience characteristics (quantitative data), so that when asking the qualitative resilience questions the researcher/interviewer could more easily prompt participants' to provide specific details related to resilience to extreme temperatures.

\section{c. Calculation of the GRI: Composite index approach}

A new theoretical and analytical approach to assess general resilience was developed using the SOC-13 scale in order to construct the GRI. The GRI includes SOC's three indicators-meaningfulness, comprehensibility, and manageability - and 13 of its subindicators. Online supplemental material section 1 presents each indicator and subindicator questions used and the answer options (a 7-point Likert scale).

The development of a GRI is novel and also contrasts with other literature that investigates resilience as an overall static capacity of individuals. The advantages of using the GRI is that it allows explorations of the factors shaping general resilience. Additionally, it can also be adapted to other threats, shocks, and events, which constitute a broad contribution of this paper. Researchers and academics should consider the use of such metrics to measure human resilience (i.e., GRI) as it constitutes a comprehensive approach to resilience that can help the development of policies and actions for increasing resilience. This research used the sense of coherence approach to assess the general resilience of individuals and ultimately for calculating the GRI. The development of such an index has potential use beyond the health literature, as results could be easily comparable within and between studies. The development of the GRI through the SOC-13 scale values constitutes a novel contribution of this research and builds on Antonovsky's (1987) work and on composite indices approaches.

This paper is part of a wider project also investigating general and specified adaptation and vulnerability (Nunes 2018, $2019 b$ ). The development of a GRI was found to be extremely useful as a means to compare general vulnerability (GVI) with general resilience (GRI). The method used for calculating the GRI incorporating the sense of coherence scale was based on the same method used for calculating the GVI. Furthermore, it is the first time that such an approach is developed to measure resilience using the SOC scale, which represents a novelty of this research. Theoretical validity of calculating the GRI in the way the GVI was calculated is justified in this research to allow coherence in the quantitative data analysis through two different theoretical concepts (i.e., vulnerability and resilience) enabling the comparison of the two sets of data.

A composite index approach was used for the development and calculation of the GRI, building on approaches of indices development (Vincent 2004; United Nations Development Programme 2007; Hahn et al. 2009; Preston et al. 2011). The GRI differs from these as it uses primary data and has an individual or sample focus. Previous approaches mostly rely on secondary data and climate models and have a regional focus. The GRI was specially developed for this study and the formulae used are presented below. To assess comparability, all indicators were standardized using the United Nations Development Programme (2007) procedure [Eq. (1)], which also guarantees that all indicators are normalized to relative positions between 0 and 1 (Vincent 2004; Hahn et al. 2009). Equation (1) is used to translate the Likert scale to index values. As a result, the values of the GRI indicators and the GRI value are derived from the following equation:

$$
\operatorname{index}_{s_{i}}=\frac{s_{i}-s_{\min }}{s_{\max }-s_{\min }} .
$$

Following the calculation of values of each of the three indicators, their weighted means were calculated using

$$
\mathrm{GRI}_{i}=\frac{\sum_{i=1}^{3} w_{M_{i}} M_{i}}{\sum_{i=1}^{3} w_{M_{i}}},
$$


TABLE 1. Qualitative data analysis process.

1) Develop all individual participants' text interview records (transcripts)

2) Taking into account preliminary themes developed from the interview protocol question and based on the research questions, read and reread the transcripts thoroughly

3) Note key themes from transcripts

4) Develop initial themes that include emergent themes, subthemes, and categories

5) Link emergent themes, subthemes, and categories to the theoretical concept of resilience

6) Review and improve the initial themes to achieve a final themes list

7) Code or recode all transcripts according to the final themes

8) Create a matrix for each participant interview transcript entailing extreme heat and cold resilience content and themes

9) Examine the matrix for the purpose of interpreting all individual participants' data and to look for similarities and differences between participants

10) Develop profiles of participants (see section $4 d$ )

11) Investigate and integrate the qualitative interpretations with the quantitative results

which can also be expressed as

$$
\mathrm{GRI}_{i}=\frac{w_{\mathrm{ME}} \mathrm{ME}_{i}+w_{\mathrm{CO}} \mathrm{CO}_{i}+w_{\mathrm{MA}} \mathrm{MA}_{i}}{w_{\mathrm{ME}}+w_{\mathrm{CO}}+w_{\mathrm{MA}}}
$$

(Hahn et al. 2009), to develop the GRI score. In Eq. (3), ME indicates meaningfulness, $\mathrm{CO}$ is comprehensibility, and MA is manageability. The weighting of each indicator depends on the number of subindicators that are part of each indicator, allowing all indicators to contribute in an equal way to the overall resilience (Sullivan et al. 2002).

In this research the GRI varies between 0 (low resilience) and 1 (high resilience) with a 0.500 midpoint. The contribution of each of the three indicators of resilience to the overall GRI value is calculated by dividing the value of the GRI of each indicator by the sum of all values of the GRI indicators.

\section{d. Assessing the specified resilience to extreme temperatures}

Specified resilience to extreme temperatures in this paper includes HRR and CRR. Qualitative semistructured interview data are used to assess individual participants' levels of resilience to extreme temperatures. Each participants' interview data were analyzed, and the three dimensions of resilience were coded as "high" or "low." The process of examining and interpreting participants' interviews was done using thematic analysis (Braun and Clarke 2006) and through an iterative and systematic coding process was used to account for the characteristics of all three indicators of resilience in each participants' transcripts. This is not without a degree of subjectivity, which was reduced by the use of a structured coding process (see Table 1). This was performed to enable defining each of the resilience indicators as "high" or "low" (Table 2), as above for the GRI and original SOC scale (Antonovsky 1987, 1993). This included the development of what is meant by high comprehensibility, high manageability, and high meaningfulness (Table 2).

Attaining such a categorization based in the qualitative interviews with the arranging and allocation of individual participants' positions required a thorough analysis of transcripts, related themes and subthemes making sure that participants' position accurately reflected participants' resilience stances. It represents a continuing process where all relevant characteristics and factors were taken into account for each participant. Subjectivity, complexity, and transparency concerns constituted limitations in categorizing participants' specified resilience. The results presented

TABLE 2. Indicators and explanation of indicators used to develop the specified resilience assessments from the SOC-13 scale.

\begin{tabular}{ll}
\hline \hline Indicators & Explanation of indicators \\
\hline Comprehensibility (CO) & High comprehensibility: When participants saw heat/cold as a nonstressor because they had previous \\
experience with extreme heat/cold temperatures and thus such temperatures did not pose a problem \\
for them \\
Low comprehensibility: When participants saw heat/cold as a stressor because they previously had difficulty \\
and bad experiences in dealing with extreme heat/cold temperatures and thus such temperatures posed a \\
problem for them \\
High manageability: Characterized by participants perceiving that they had assets available to them either \\
at their direct or indirect control that they needed to deal with the threat/stress that heat/cold poses to \\
them, and thus they did not feel like victims to such extreme temperatures \\
Low manageability: Characterized by participants perceiving that they did not have enough assets available \\
to them either at their direct or indirect control that they needed to deal with the threat/stress heat/cold \\
poses to them, and thus they felt like victims to such extreme temperatures \\
High meaningfulness: When participants felt confident that one was able to deal with the heat/cold and felt \\
motivated to deal with it because it was seen as an important area of their lives \\
Low meaningfulness: When participants did not feel confident that one was able to deal with the heat/cold \\
and did not feel motivated to deal with it because it was seen as an unimportant area of their lives \\
Meaningfulness (ME)
\end{tabular}




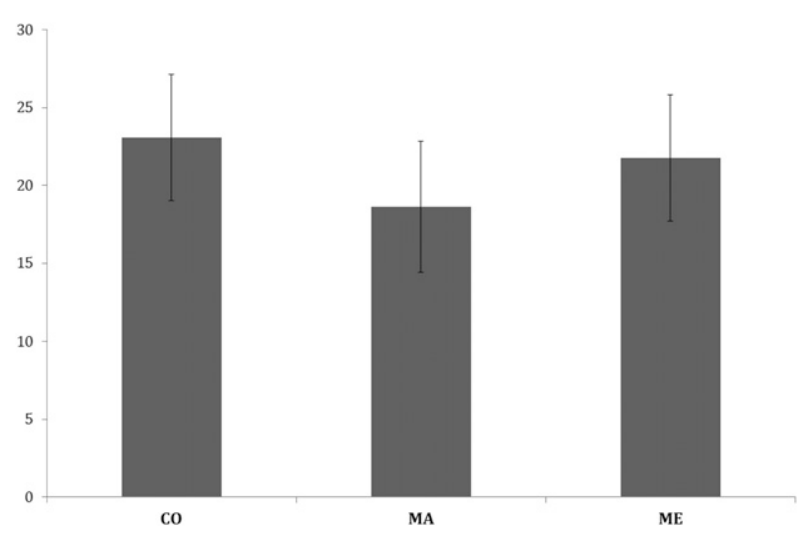

FIG. 1. Comparison of general resilience (SOC) score with the three subscales [comprehensibility (CO), manageability (MA), and meaningfulness (ME)].

below are replicable as very concrete definitions of comprehensibility, manageability, and meaningfulness were used when undertaking thematic analysis.

Specified resilience was assessed through the following procedure: participants high in at least two resilience indicators are considered as having high specified resilience and participants high in one or no resilience dimensions were considered to have low specified resilience.

\section{Results}

\section{a. General resilience}

The sense of coherence short scale (SOC-13) was used to quantitatively assess the general resilience of the study's sample. Participants' general resilience (SOC) scores ranged from 38 to 82 (13 being the lowest possible score and 91 being the highest possible score, with the mean of the scale being 52), with a score of $63.43 \pm 9.82$ (mean \pm standard deviation). This result indicates that most participants had high general resilience. Comprehensibility (CO) subscale scores ranged from 15 to 32 , with a score of $23.06 \pm 4.21$ (mean \pm standard deviation). Manageability (MA) subscale scores ranged from 9 to 26, with a score of $18.63 \pm 40.5$ (mean \pm standard deviation). Meaningfulness (ME) subscale scores ranged from 9 to 28 , with a score of $21.75 \pm 4.07$ (mean \pm standard deviation) (Fig. 1). These results show that overall participants in this study revealed higher ability to make sense of their lives (CO) and motivation to respond to life threats (ME) and lower availability and access to assets (MA).

The method used for calculating the GRI incorporating the sense of coherence scale was described in section $3 \mathrm{c}$ and it is the first time that such approach is developed to measure resilience using the SOC scale, which represents a novelty of this research. Transforming the SOC scores into a GRI is novel and has not yet been attempted elsewhere.

The value of the GRI for the study's sample was 0.647 (Table 3) [values range from 0 (less resilient) to 1 (more resilient)]. This indicates that the sample had high general resilience (values equal or higher than 0.500 , the midpoint). Cronbach's alpha, a coefficient of internal consistency (Tavakol and Dennick 2011), was calculated to estimate the reliability of the index and to show the amount of measurement error in the GRI (Cronbach's alpha = 0.741). It is expressed as a number between 0 and 1 ; as the value increases (i.e., closer to 1 ) the estimate of reliability increases and the proportion of the index score that is attributable to error will decrease (Tavakol and Dennick 2011). The sample exhibited greatest resilience on the meaningfulness indicator $(0.741)$, followed by manageability (0.609) and comprehensibility indicators (0.602) (Table 3). Table 3 shows how the Likert scale was translated into index values. The results of the indicators values are presented in Fig. 2 as a radar chart portraying the values of the indices as presented above.

The resilience dimensions contributing to general resilience are shown in Fig. 3. The greatest contributor is meaningfulness (38\%), followed by comprehensibility (31\%) and manageability (31\%).

The majority of participants were high on the three dimensions of general resilience and general resilience (high CO: 71\%; high MA: 71\%; high ME: 94\%; and high GRI: $84 \%$ ) (Fig. 4 and online supplemental material section 2).

The GRI was slightly higher in male participants and in the oldest age group $(85+)$ and was lower for single and widowed participants. In addition, GRI scores were slightly lower for those living alone as well as for one participant living with other nonrelatives. More literate participants and those with higher income and better financial situation had a higher GRI.

\section{b. Specified resilience}

The overall resilience themes arising from the heat- and cold-related qualitative interviews are presented in Table 4. The themes were organized around the three dimensions of resilience and reflect older people's resilience characteristics in

TABLE 3. Summary of calculations of the GRI and its indicators (comprehensibility, manageability, and meaningfulness).

\begin{tabular}{|c|c|c|c|c|}
\hline & \multicolumn{3}{|c|}{ SOC (Likert scale) } & \multirow[b]{2}{*}{ GRI value ${ }^{\mathrm{a}}$} \\
\hline & Sample value & Max possible value & Min possible value & \\
\hline Comprehensibility & 23.059 & 35 & 5 & 0.602 \\
\hline Manageability & 18.627 & 28 & 4 & 0.609 \\
\hline Meaningfulness & 21.784 & 28 & 4 & 0.741 \\
\hline Overall & 63.471 & 91 & 13 & 0.647 \\
\hline
\end{tabular}

${ }^{\mathrm{a}}$ Calculations-Step 1 (repeat for all component indicators): [Eq. (1)] $\operatorname{index}_{s_{i}}=\left(s_{i}-s_{\min }\right) /\left(s_{\max }-s_{\min }\right)$; index comprehensibility $(\mathrm{CO})=(23.059-$ $5) /(35-5)=0.602$. Step 2: [Eq. (2)] $\mathrm{GRI}_{i}=\sum_{i=1}^{3} w_{M_{i}} M_{i} / \sum_{i=1}^{3} w_{M_{i}}$ [also expressed as Eq. (3)]; $\mathrm{GRI}_{i}=\left(w_{\mathrm{ME}} \mathrm{ME}_{i}+w_{\mathrm{CO}} \mathrm{CO}_{i}+\right.$ $\left.w_{\mathrm{MA}} \mathrm{MA}_{i}\right) /\left(w_{\mathrm{ME}}+w_{\mathrm{CO}}+w_{\mathrm{MA}}\right)=[(4)(0.741)+(5)(0.602)+(4)(0.609)] /(4+5+4)=0.647$. 


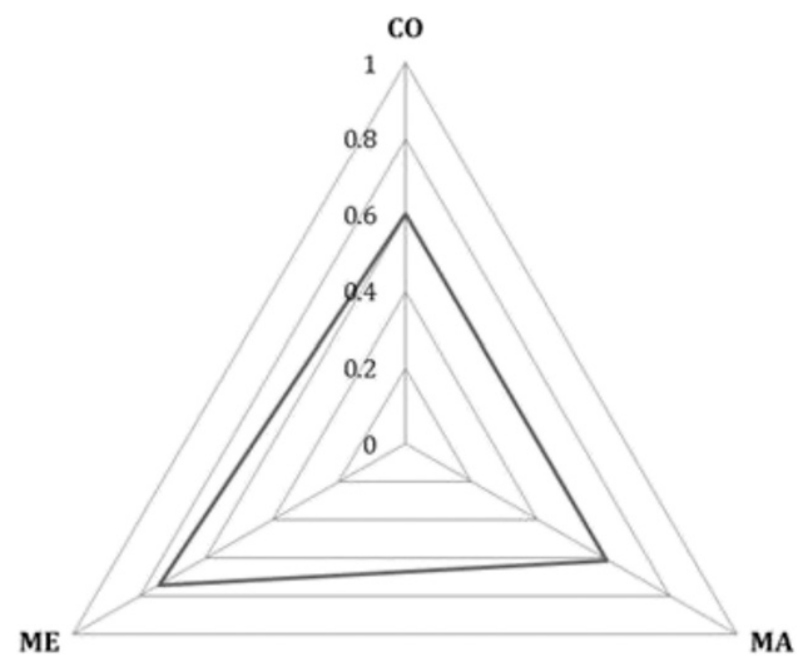

FIG. 2. GRI radar chart for the overall sample.

terms of cognitive (comprehensibility), instrumental/behavioral (manageability), and motivational (meaningfulness) features when dealing with extreme temperatures. Many of the themes were similar to both extreme temperatures. Despite this, some differences were found that relate to the levels of predictability (comprehensibility) that were lower for cold than heat, availability of assets (manageability) was found to be higher for heat than cold and availability of strategies (meaningfulness) to deal with cold lower than heat.

The majority of participants revealed high heat-related comprehensibility ( $89 \%$ ), followed by high meaningfulness (67\%) and high manageability (58\%). Overall, the majority of participants revealed high heat-related resilience (62\%). These findings suggest that most participants viewed heat as being predictable and explicable (comprehensibility), with which they had assets available to deal (manageability), and to which they invested their efforts in order to be able to respond (meaningfulness) (Fig. 5 and online supplemental material section 3).

The majority of participants revealed high cold-related comprehensibility $(87 \%)$ and half of participants revealed high meaningfulness (50\%) (Fig. 6 and online supplemental material section 4). Fewer participants revealed high manageability (33\%), and the majority revealed low cold-related resilience (52\%).

\section{c. Dimensions of general and specified resilience}

\section{1) COMPREHENSIBILITY}

The general resilience results illustrate that most participants had a high level of belief that the problems and challenges in their lives are structured, ordered, explicable and understood (e.g., illness, death of a loved one, own death) (indicator value: 0.602; ranging from 0 as least comprehensible to 1 as most comprehensible). The majority of participants felt that when something happened, they generally saw things in the right proportion (63\%). Only a minority feel that they are in an unfamiliar situation not knowing what to do (16\%).

The specified resilience results (heat- and cold-related) revealed two main themes. The first theme—predictability — was

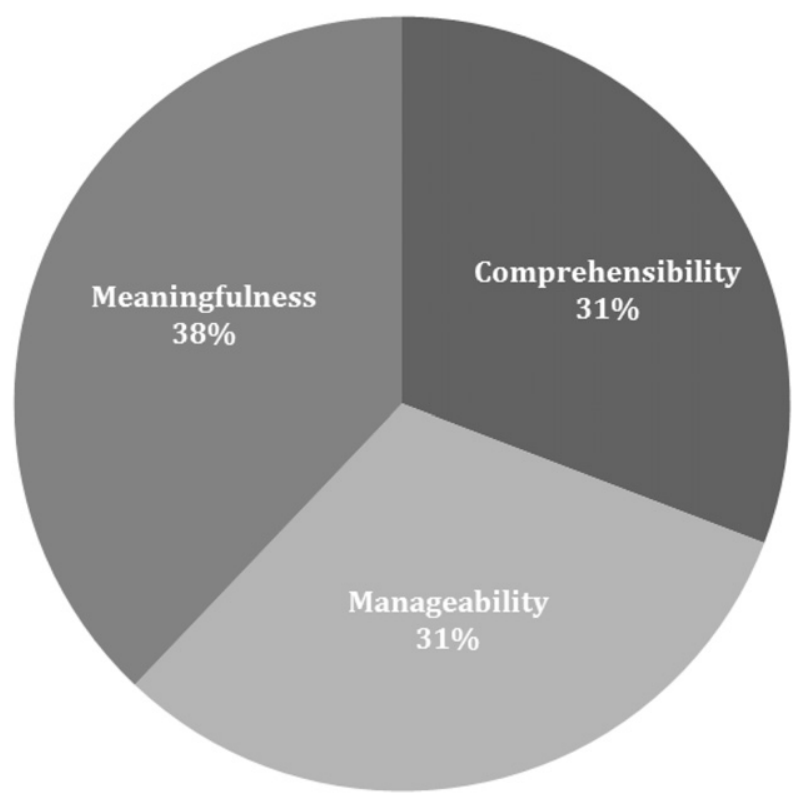

FIG. 3. Resilience dimensions contribution to overall GRI for the overall sample.

associated with participants' high comprehensibility of both extreme temperatures. Participants' revealed a structured, expectable, and explainable understanding of the occurrence of extreme temperatures in their lives. These participants were able to make sense of the stress they posed in their lives, especially in relation to heat but not as much regarding cold. They had confidence and were more positive in perceiving their ability to meet the challenges extreme temperatures posed to them, as expressed, for example, by participant GM, a 69-yr-old male:

Well, I guess that there's the idea that people deal better and somewhat more easily with very hot weather.

The second theme-misfortune-was linked with participants who displayed low heat- and cold-related comprehensibility. Such participants saw extreme temperatures as uncertain, inexplicable, uncontrollable, and "chaotic" events that added high levels of stress, making them hopeless and helpless. This resulted in participants' inability to make sense of the challenges extreme temperatures posed to them and therefore an inability to deal with them, as exemplified by this response:

I feel I deal very badly. When it's not very hot it's already bad, but when it is really hot, I don't know ... it is a nightmare, I can't stand any clothes, I don't eat. (participant KM: male, age 65 years)

\section{2) Manageability}

With regard to general resilience, participants had a high level of perception that assets are available to them to face the problems and challenges in their lives (indicator value: 0.610; ranging from 0 as least manageable to 1 as most manageable). Only a minority of participants indicated they had been disappointed by people whom they counted on most (37\%), felt that they were 


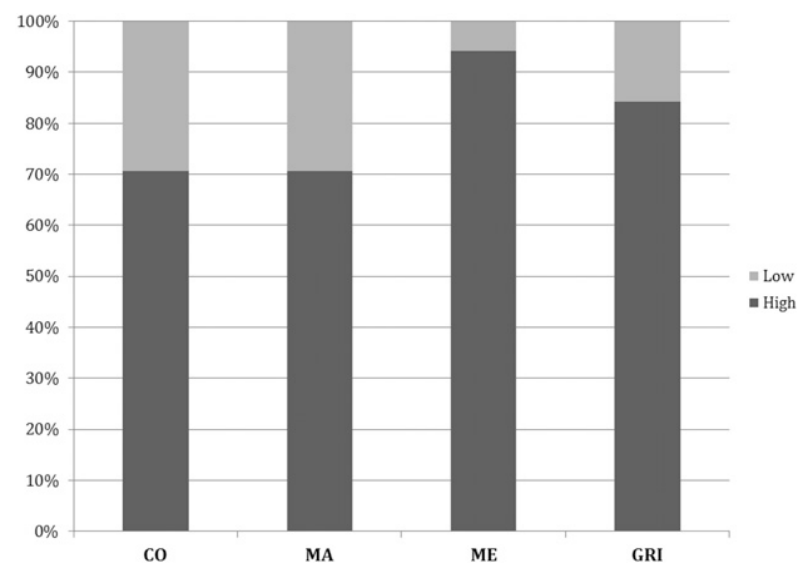

FIG. 4. Distribution of participants according to high and low general resilience dimensions and GRI. The $y$ axis represents the percentage of participants exhibiting high and low general resilience.

treated unfairly $(20 \%)$, and felt that they were not sure they can keep under control (14\%).

Specified resilience findings revealed two main emergent themes. The first theme-managing — was mentioned by participants with high manageability to extreme temperatures. Participants' manageability to both extreme temperatures was very diverse. Participants who perceived having greater quantity and variety of assets under their direct or indirect control (e.g., family and friends) did not feel victims of the threats these events posed to them as they could easily access the assets needed to respond. Most frequently mentioned assets included physical assets (using fans or air conditioning) and place-based assets (accessing cooler places). Overall, having human assets, such as mental and physical abilities, were widely mentioned in relation to both extreme temperatures as being crucial for accessing and being able to use other types of assets, as in this response:

Yes, I have [assets], but even if I didn't I would make sure I would get them. (participant FF: female, age 80 years)

The second theme-vulnerabilities and struggling —-was linked to the low manageability of some participants who were negative about the availability of assets, especially about not having assets under their direct and indirect control to effectively respond to extreme temperatures. These participants felt they could only count on themselves and no one else. Limitations were found on all types of assets: financial assets (low income and savings), physical assets (lack of housing insulation), social assets (not having family, friends or neighbors they could count on), placebased assets (not having help from local authorities), and human assets (having low health status). These participants felt less able to deal and respond to them due to lack of assets. Extreme cold posed more stress on participants' assets than extreme heat, partly because of the perceived need for more assets. The use of energy was found to be essential to keep themselves and the house warm. The high costs of electricity and gas, and the lack of home insulation, highlighted how access to more assets (financial, place based, and social) is necessary to enable them to better deal with extreme cold. An example is seen in this response:
I have to have [enough assets], if I don't have I won't be able to live. There is always the financial issue that affects all of us ... we can't do everything we want as we don't have assets for that. We improve things slightly, but beyond that we're not able to do anything else. (participant MM: male, age 85 years)

\section{3) MEANingfulnESS}

General resilience findings revealed that within the four items comprising meaningfulness the sample had very high levels of investment, engagement and commitment to deal with the problems and challenges they face in their lives (indicator value: 0.740; ranging from 0 as least meaningful to 1 as most meaningful). Most participants felt that doing the things they do every day is a source of pleasure and satisfaction (79\%), that their life has had clear goals and purpose $(71 \%)$. Only some felt that they do not really care about what goes on around them $(22 \%)$ and that there is little meaning in the things they do in their daily life (12\%).

Specified resilience findings revealed two main emergent themes. The first theme-drive and investment-emerged from participants scoring high on meaningfulness. These participants were motivated and interested in adapting to extreme temperatures. Such participants were thus positive about their ability to adapt by dealing the best way possible to the challenges that extreme temperatures pose to their lives:

I deal well with everything, even if it's very cold. I'm that kind of person. We deal with everything as it happens. [. . .] We have to deal and find solutions. (participant ZF: female, age 79 years)

The second theme-helplessness, hopelessness, and avoidance of threat-was linked to participants' low meaningfulness. These participants were not motivated or interested in dealing with extreme temperatures and felt helpless and hopeless when they occurred. They were particularly negative and avoided the challenges of extreme temperatures by not thinking about them, felt unable to do anything and did nothing to deal with them. This was particularly prominent for extreme cold-related resilience, as shown in this response:

$\mathrm{Oh}$, and what am I supposed to do?!? If it's very cold I wrap myself in clothes and drink hot things to feel a bit better . . I I can't go out, because it's very cold ... So, what can I do more? (participant RF: female, age 79 years)

\section{d. Profiles of resilience}

Profiles of individual participants were developed to present as well as integrate both quantitative and qualitative interview data. All profiles were developed using participants' interview data, by reading each transcript and selecting the most characteristic parts (Seidman 1998), and to bring to life participants' individual characteristics, as each participant represents a unique pool of resilience characteristics that can be underrepresented when looking at overall sample data. A review of individual participants' transcripts (phases 1, 2, and 3) was undertaken to develop individual participants' profiles. These profiles correspond to individual participants in this research and portray their "real" resilience characteristics as obtained from their transcripts. 
TABLE 4. Themes related to resilience arising from the heat and cold qualitative interview data according to the three resilience dimensions.

\begin{tabular}{|c|c|c|}
\hline Comprehensibility & Manageability & Meaningfulness \\
\hline \multicolumn{3}{|c|}{ Extreme heat } \\
\hline Predictability of extreme heat & Availability of assets & $\begin{array}{l}\text { Heat as an important and significant } \\
\text { feature of everyday life that requires } \\
\text { investment }\end{array}$ \\
\hline Recent experiences and memories of heat & Assets mostly under one's direct control & $\begin{array}{l}\text { Need to actively engage in heat-adaptive } \\
\text { behaviors }\end{array}$ \\
\hline $\begin{array}{l}\text { Awareness of the effects of heat health } \\
\text { impacts }\end{array}$ & Preferable direct control over assets & $\begin{array}{l}\text { Other life pressures requiring investment } \\
\text { limit engagement with heat prevention } \\
\text { measures (e.g., financial difficulties, } \\
\text { bereavement, depression, and/or } \\
\text { isolation) }\end{array}$ \\
\hline \multirow[t]{3}{*}{$\begin{array}{l}\text { Perceived ability to deal with the heat, to } \\
\text { acclimatize, and to respond and adapt }\end{array}$} & $\begin{array}{l}\text { Heat threatens certain types of assets, } \\
\text { particularly human (low health status), } \\
\text { physical (hot homes), and financial } \\
\text { (cooling devices) }\end{array}$ & $\begin{array}{c}\text { Availability of strategies to deal with heat } \\
\text { now and hypothetically in the future }\end{array}$ \\
\hline & $\begin{array}{l}\text { Barriers: low income; high electricity costs; } \\
\text { lack of insulation/hot house; fans and air } \\
\text { conditioning are bad for health }\end{array}$ & Perceptions of adaptability \\
\hline & & Perceptions of ability to act \\
\hline \multicolumn{3}{|c|}{ Extreme cold } \\
\hline Low predictability of extreme cold & Unavailability of assets & $\begin{array}{l}\text { Cold as an important and significant } \\
\text { feature of everyday life; difficult to } \\
\text { enact responses (including investments) } \\
\text { to deal with it }\end{array}$ \\
\hline $\begin{array}{l}\text { Experiences and memories of cold in the } \\
\text { past but not recently }\end{array}$ & Assets mostly under one's direct control & $\begin{array}{l}\text { Other pressing facets of life requiring } \\
\text { investment limit engagement in cold } \\
\text { prevention measures (e.g., financial } \\
\text { difficulties, bereavement, depression, } \\
\text { and/or isolation) and undermine } \\
\text { resilience }\end{array}$ \\
\hline $\begin{array}{l}\text { Lack of awareness of the effects of cold on } \\
\text { health }\end{array}$ & Preferable direct control over assets & $\begin{array}{c}\text { Lack of availability of strategies to deal } \\
\text { with the cold now and in the future }\end{array}$ \\
\hline \multirow{2}{*}{$\begin{array}{l}\text { Perceived ability to deal with the cold } \\
\text { because it is not usual and is not thought } \\
\text { as being a threat }\end{array}$} & $\begin{array}{l}\text { Improvement of individuals' assets } \\
\text { portfolio needed }\end{array}$ & \\
\hline & $\begin{array}{l}\text { Cold threatens certain types of assets-in } \\
\text { particular, physical (cold homes) and } \\
\text { financial (heating devices) } \\
\text { Barriers: low income; lack of insulation/cold } \\
\text { house; only able to heat one room }\end{array}$ & \\
\hline
\end{tabular}

The goal of these profiles is to explicitly illustrate individuals' resilience characteristics to exemplify how different participants' lives reveal specific general and heat- and cold-related resilience profiles. The three dimensions of resilience (CO, MA, and $\mathrm{ME}$ ) are also represented in the profiles, enabling a better understanding of what each of these represent in terms of actual participants' characteristics.

Individual resilience profiles of two participants (KM, GGF) are developed from their interview transcripts and presented in Figs. 7 and 8, as an illustration of the diversity of their general and heat- and cold-related resilience.

\section{Discussion}

Evidence was found that participants generally possessed high levels of general resilience. Despite this, specified resilience was found to be lower than general resilience. This is perhaps not surprising given that the SOC is a general coping measure. Additionally, the observed differences could also be due to the different types of assessment used (quantitative and qualitative). Nevertheless, in psychology for example, in the last two decades researchers have begun to rely less on encompassing types of assessments as some authors consider they do not downscale well and are not good indicators of specific circumstances such as dealing with extreme temperatures. For example, instead of trying to work with an unwieldy, broad concept of generalized self-efficacy (Schwarzer and Jerusalem 1995), researchers have begun to look at self-efficacy in specific circumstances (Pajares 1996). Similarly, others consider it is less meaningful or useful to think of an overall risk-taking personality (or sensation-seeking or thrill-seeking person; Zuckerman 1979) if one is interested in, 


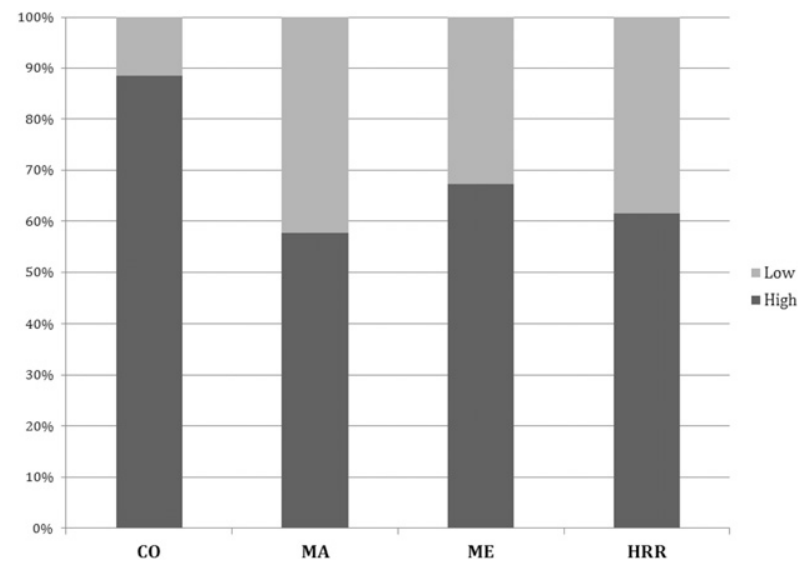

FIG. 5. Distribution of participants according to high and low heat-related resilience dimensions and HRR. The $y$ axis represents the percentage of participants exhibiting high and low heat-related resilience.

for example, taking specific risks (i.e., cars or the style of driving). Instead, risk-taking seems to be specific to certain circumstances (Weber et al. 2002). Similarly, for fear, it is possible to measure it at a broad level (e.g., trait neuroticism, which is quite general), but similarly to all other broad measures, this may say little about the level of fear a person experiences in a specific situation (e.g., heights). In summary, individuals can have different types of specific particularities and have specific behavioral responses with no indication that this may result from a broad-based measure. Nevertheless, this is not to say that general constructs such as the SOC are not useful or that they do not have advocates (Schwarzer and Jerusalem 1995).

Sources of general and specified resilience were found to be varied and diverse as well as dependent on cognitive, behavioral, or instrumental and motivational factors in older people's internal and external environments. The findings reported here reveal how believing that the threats and challenges are structured and ordered (comprehensibility), perceiving that assets are available for one to face the threats and challenges (manageability), and feeling it is worth investing in dealing with these (meaningfulness) are sources of general and specified resilience.

Resilience to extreme heat was related to the predictability of heat, perception of available assets ready to be used, and the wish to keep cool by investing in available actions. On the other hand, resilience to extreme cold was found to be associated with both apathy and anxiety toward cold as participants either did not see cold as a threat or saw it as a burden, respectively. Participants found it hard to be motivated to deal with the cold mainly due to lack of assets available, in particular, financial (lack of affordable heating), physical (lack of thermal insulation), and social assets (lack of social connections and ties).

Both extreme temperatures posed challenges to resilience. Specified resilience had links with general resilience, but its relationship was not straightforward. Some participants with a high general resilience did not think that experiencing and living through extreme temperatures was comprehensible, manageable, and/or meaningful, resulting in low specified resilience. Participants set boundaries on what matters in their lives and

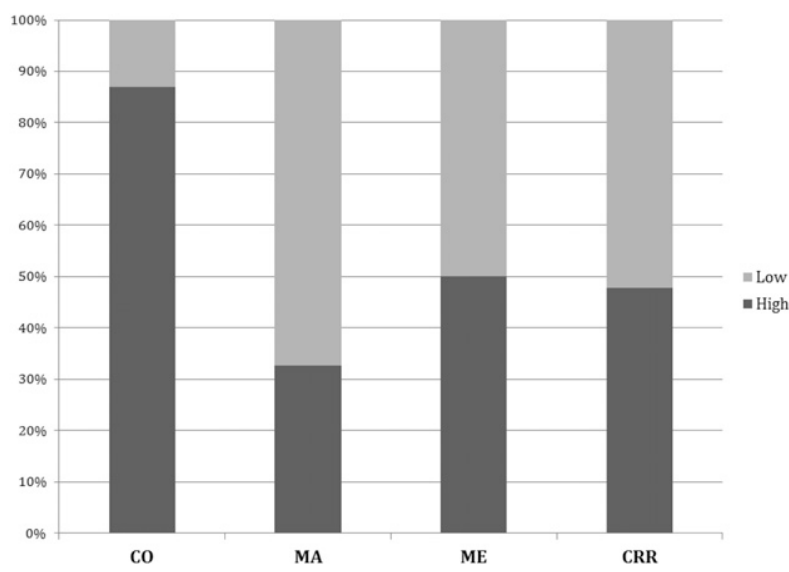

FIG. 6. As in Fig. 5, but for CRR.

what lies outside these boundaries, even if comprehensible, manageable, and meaningful, is not thought as important and does not materialize into something worth investing in. As a result, having high general resilience may or may not mean having high specified resilience.

Different facets of participants' lives shaped their specified resilience that included perceptions of their own vulnerability to the adverse effects of extreme temperatures, perceptions of the vulnerability to extreme temperatures, perceived ability to deal with the threat, and agency in actively dealing with the threat. They were all related to the three dimensions of resilience and constitute opportunities to increase resilience and understand barriers that need to be controlled and/or eliminated for increasing resilience in dealing with such events.

Believing that extreme temperature events could be ordered and understood was related with high levels of comprehensibility, and perceiving one had the assets at one's own disposal or under the control of trusted others (family, friends, and neighbors) to keep cool or warm were the major determinants of manageability, while meaningfulness was ultimately dependent on feeling able to deal with the event and having the willingness to invest and mobilize the assets available. Extreme temperatures created stress in participants' lives and put to the test their cognitive (comprehensibility), instrumental/behavioral (manageability), and motivational (meaningfulness) indicators of resilience.

The findings of this study support suggestions in international studies that access to and availability of assets play a determinant role in the resilience of individuals in adapting to climate change (Haq et al. 2008; Royal Society 2014; Nunes $2018,2019 b)$. The results are also comparable to those presented by Haq et al. (2008) who argue that having physical and financial as well as social assets (e.g., social contacts and networks), place-based assets (e.g., transport), and human assets (e.g., knowledge) contributes to the resilience of older people in adapting to climate change.

Furthermore, these findings are in agreement with the literature asserting that older people's resilience is an enabler for adaptation (Conlon et al. 2011; Hansen et al. 2011).

The limitations of the application of the SOC approach are that no examples exist of its use with threats such as extreme 


\section{High general resilience, Low heat-related resilience \& High cold-related resilience participant - KM}

$\mathrm{KM}$ is 65 years old, is married and lives with his wife and daughter at their owned bungalow.
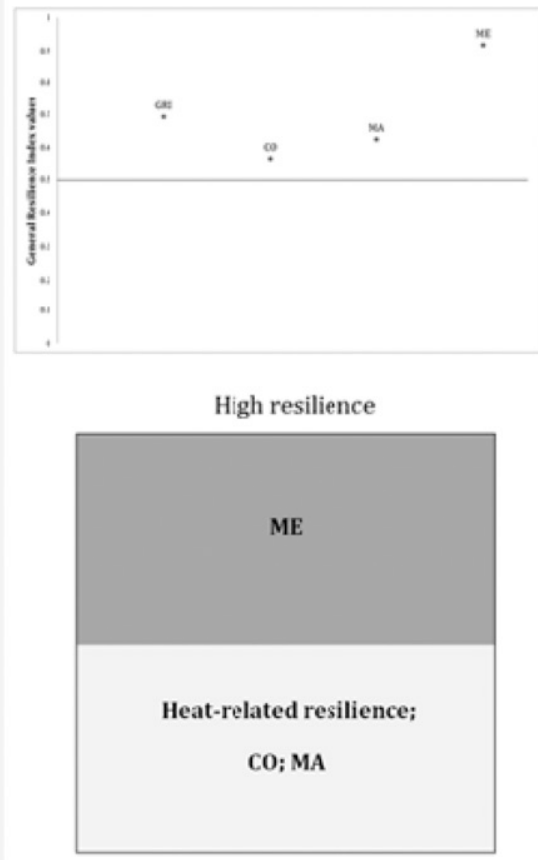

Low resilience

High resilience

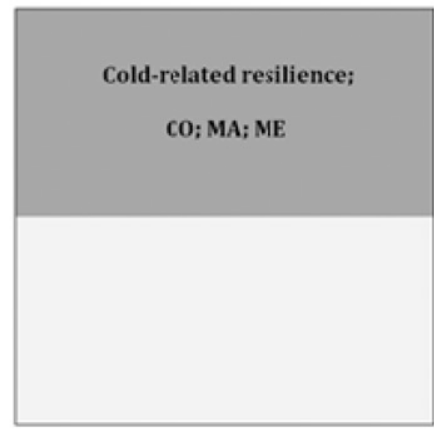

Low resilience

KM very seldom or never feels that he is in an unfamiliar situation and does not know what to do, nor has mixed-up feeling and ideas, but when something happens he has generally found that he overestimates or underestimates its importance ( $\mathrm{CO})$. He very seldom or never feels that he is being treated unfairly (MA). KM very seldom or never feels that he does not care about what goes on around him and until now his life has had very clear goals and purpose, plus doing the things he does every day is a source of deep pleasure and satisfaction (ME).

KM deals very badly with very hot weather and for him it is a very stressful time, which he feels disrupts his life and is very bad to his health. He feels very anxious and confused during very hot weather and sees it as a very complex problem (CO). It is very difficult for him to respond to heat. He does not feel that he has enough assets to be able to efficiently engage in heat prevention measures and behaviours. He would like to have air conditioning fitted in his home, as well as double glazing windows and a new roof as his home lacks insulation. $\mathrm{He}$ is very concerned with the related costs despite finding that these changes would improve his and his family living conditions and ability to keep cool indoors, as some of his neighbours have done it and feel they can now keep their home cool and feel cool at home (MA). He has thought about going ahead with improving insulation in his home but has not decided to do it yet, but thinks he will do it soon as he feels that heat-related hazards are becoming more frequent and intense which makes it harder for him to deal with it if his house is not properly insulated (ME).

$\mathrm{KM}$ feels that cold is predictable, that the challenges it poses are clear and structured, and he deals well with it (CO). He feels he has all the assets needed at his disposal to deal well with the cold, as he has a fireplace in his home that keeps it very warm (MA). He is motivated to dealing with the cold and would like to have more information on how to better protect his health from the impacts of cold (ME).

General Resilience: 0.692; CO: 0.567; MA: 0.625; ME: 0.917; Heat-related resilience: Low; CO: Low; MA: Low: ME: High; Type: LLH; Prediction: pressure to move up; Cold-related resilience: High; CO: High; MA: High; ME: Hiqh;

FIG. 7. Participant KM resilience profile. 


\section{High general resilience, High heat-related resilience \& Low cold-related resilience participant - GGF}

GGF is 84 years old, is widowed and has no children. She lives alone in a rented studio apartment in a building owned and run by a charity.

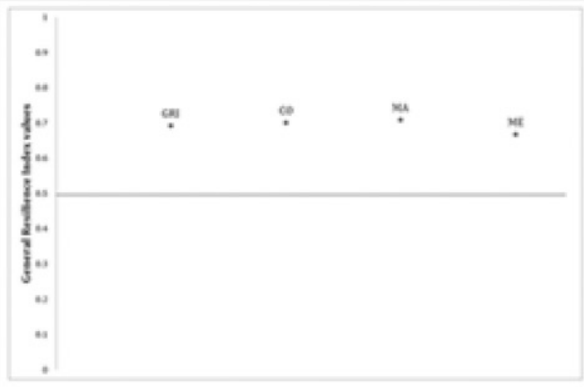

High resilience

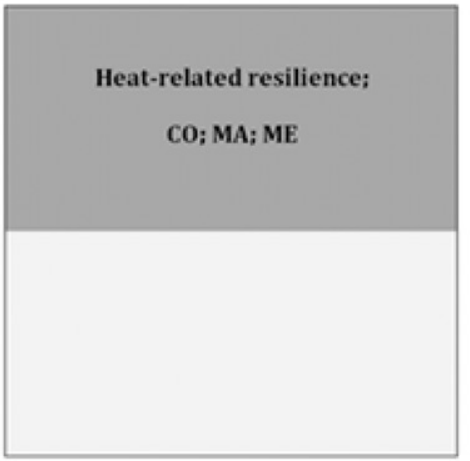

Low resilience

High resilience

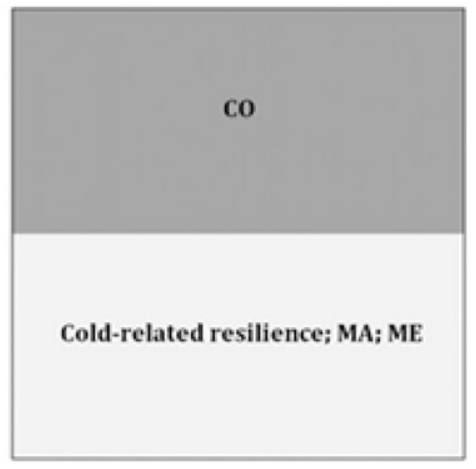

Low resilience
GGF is a very positive person and used humour several times when talking about her life events and circumstances. Very seldom or never she has the feeling that she is in an unfamiliar situation and does not know what to do, plus when something happened she saw things in the right proportion and very seldom or never she has feelings inside her she would rather not feel (CO). GGF very seldom or never feels she is being treated unfairly (MA) and she very seldom or never has the feeling that she does not really care about what goes on around her. Until now, her life has had no clear goals or purpose at all but doing the things she does every day is a source of pleasure and satisfaction. She very seldom or never has the feeling that there is little meaning in the things she does in her daily life (ME).

GGF feels she deals with the heat the best she can as it has a will of his own. To her heat is predictable and an ordered event in her life (CO). She feels she has all the assets needed to respond well (MA). She thinks she is capable to deal well with very hot weather and searches for ways to improve the way she deals with it (ME).

GGF feels she has to conform, endure the cold but she feels hope and sees it as a challenge in her life (CO). She feels she has some assets to deal with the cold as where she lives there are heating devices in a common room but no one stays there the whole day to keep warm. Thus, as her home is very cold and damp she would like to have more assets such as be able to use heating devices in her own home and afford paying electricity bills in order to respond better to the cold (MA). She feels demotivated during very cold weather as she does not see where she could improve the way she responds to cold (ME).

General Resilience: 0.692; CO: 0.700; MA: 0.708; ME: 0.667; Heat-related resilience: High; CO: High; MA: High: ME: High; Type: HHH; Prediction: stable; Cold-related resilience: Low; CO: High; MA: Low; ME: Low;

FIG. 8. Participant GGF resilience profile. 
temperatures until now. However, it has been used to access the resilience of individuals to other events such as war (e.g., Almedom et al. 2007; Kimhi et al. 2010) and a hurricane (Glandon et al. 2008). Recently, it is gaining more interest and is considered to be an accepted measure of individual resilience (e.g., Kimhi 2016). Despite this, interest in the SOC approach is still limited largely to the health research field; it has potential for application to studies focusing on a breadth of stresses, shocks, and threats to individuals. An additional limitation results from the fact that due to being the first time that resilience to extreme temperatures has been investigated through a transformation of the SOC scale, there is no possibility to compare the findings of this research with other studies.

Original contributions of this study include the development and implementation of a mixed-methods approach to operationalize general and specified resilience and using the SOC in the context of extreme temperatures. Furthermore, this research offers additional contributions by adapting the SOC scale (quantitative) to qualitatively assess specified resilience to extreme temperatures and using an asset-based approach to operationalize manageability one of the determinants of resilience (the instrumental or behavioral dimension, defined as the perception of availability of resources/assets to face the threat and the power to do so). Another contribution of this study relates to the development of a conceptual and analytical framework, as well as a methodological approach that can be replicated at the national, regional, and local levels, by local authorities, nongovernmental organizations (NGOs), health trusts, among others to better understand the needs, constraints, limits and opportunities to enhance resilience for improving adaptation (Nunes 2018) and reducing vulnerability (Nunes 2019b) to extreme temperatures in particular, with important insights for other threats, shocks, and stresses in general.

This paper developed a coherent and comprehensive conceptual, as well as empirical account for understanding general and specified resilience (i.e., to extreme temperatures). In doing this, it provides a complete account of how to support actions to move forward on ways to increase resilience, as well as tools to help strengthening its implementation. This research is novel because of its 1) conceptual novelty-it reinterprets conceptual findings to assess general and specified resilience, 2) empirical novelty-it develops a quantitative measure of general resilience and qualitative assessments of specified resilience for improving the understanding of the factors that influence resilience, and 3) practical novelty-it provides an improved, more coherent account of what a resilient individual looks like. This research has the potential to inform, provide evidence, and influence government, academia, the third sector, and the wider public in exploring alternative ways of improving general and specified resilience to extreme temperatures.

The research carried out in this paper and the findings obtained have highlighted prospects for further research focusing on resilience to a variety of domains (e.g., environmental, cultural, societal, and individual challenges). An extension of this research is to encourage effective interdisciplinary work. Further opportunities also exist to develop similar case studies in other locations, settings, and other groups of interest. Other potential areas for further research arise from the conceptual choices and analytical findings of this research. Building on these, further research possibilities, could expand from the conceptual and methodological choices implemented here and explore resilience not relying so much on the SOC as it exists generally and to try to downscale all (even with the GRI) but rephrase the SOC items so that they focus specifically and directly on meaningfulness, manageability, and comprehensibility as this relates to extreme temperatures.

\section{Conclusions}

This paper investigated the determinants of general and specified resilience to extreme temperatures through the development of a general resilience index (GRI), heat-related resilience (HRR), and cold-related resilience (CRR) assessments. This approach contrasts with other literature that investigates resilience as an overall static capacity, which also tends to be disciplinary focused.

The unequal frequency and intensity of extreme heat (i.e., higher) and extreme cold (i.e., lower) temperatures in Lisbon has implications for the degree to which older people feel able to deal with such events. Individualized and tailored actions for increasing general and specified resilience are needed to take into account regional and local contexts. This has implications for addressing the resilience of individuals to different threats, as participants in this research revealed different levels of general and specified resilience. As a result, older people can be resilient to one type of threat and not to another.

This study indicates that planning, development and implementation of policies and actions aiming at strengthening resilience and improving adaptation are possible and deemed necessary. Achieving this requires short-, medium-, and longerterm political commitment, investment, and funding to support national and local policy decisions and interventions for developing tailored actions for increasing general and specified resilience.

Concrete policy recommendations could take the form of programs, plans, and actions supporting individuals to enable them to better deal with challenging life events through peopleor community-centered approaches linked to specific priorities, problems, and needs. Resilience policies and strategies could focus on improvements in physical assets available to older people, such as home insulation and provision of cooling and heating devices/systems, as well as financial assets, such as reduction of gas and electricity prices. In addition, policies aiming at improving social assets, such as social activities to improve social networks, and place-based assets for better access to public green and blue spaces for cooling and public indoor spaces for cooling and heating.

Because the findings of this research highlighted high levels of trust and support older people receive from local authorities, opportunities could thus arise from the restructure and implementation of integrated structures where health and social care professionals, housing officers and solicitors work together under the "same roof" using a person-centered approach to provide advice and care to the whole population, not only to older people for improving resilience to extreme temperatures. Prospects for linking resilience and adaptation to extreme temperatures also exist through links with the 2030 Sustainable 
Development Agenda through the Sustainable Development Goal (SDG) 3 on good health and well-being and existing interactions with other SDGs (i.e., SDG7-affordable and clean energy; SDG11-sustainable cities and communities) (IPCC 2018; Nunes et al. 2016).

Opportunities for further research may include investigating the resilience of individuals and communities to different threats (i.e., wildfires, drought, and floods), in different locations, and with other groups of interest. An additional avenue for future research could involve policy makers through the presentation of these findings and discussion of how they may be taken forward to inform policy, which would be key to transform research into practice for strengthening resilience and improved adaptation to extreme temperatures.

Acknowledgments. The author thanks all participants for their involvement throughout all phases of the research.

\section{REFERENCES}

Adger, W., 2000: Social and ecological resilience: Are they related? Prog. Hum. Geogr., 24, 347-364, https://doi.org/ 10.1191/030913200701540465.

Almedom, A., 2005: Resilience, hardiness, sense of coherence, and posttraumatic growth: All paths leading to "light at the end of the tunnel"? J. Loss Trauma, 10, 253-265, https://doi.org/ 10.1080/15325020590928216.

_ 2009: A call for a resilience index for health and social systems in Africa. The Frederick S. Pardee Centre for Study of the Longer-Range Future 10 Doc., 8 pp., http://www.bu.edu/ pardee/files/2009/10/pardee-iib-10-oct-09.pdf?PDF = policy010resilience-index/

— and D. Glandon, 2007: Resilience is not the absence of PTSD any more than health is the absence of disease. J. Loss Trauma, 12, 127-143, https://doi.org/10.1080/15325020600945962.

—- and J. Tumwine, 2008: Resilience to disasters: A paradigm shift from vulnerability to strength. Afr. Health Sci., 8 (S1), S1-S4.

_ B. Tesfamichael, Z. Saeed Mohammed, C. Mascie-Taylor, and Z. Alemu, 2007: Use of 'sense of coherence (SOC)' scale to measure resilience in Eritrea: Interrogating both the data and the scale. J. Biosoc. Sci., 39, 91-107, https://doi.org/ 10.1017/S0021932005001112.

Almeida, S., E. Casimiro, and J. Calheiros, 2010: Effects of apparent temperature on daily mortality in Lisbon and Oporto, Portugal. Environ. Health, 9, 12, https://doi.org/10.1186/ 1476-069X-9-12.

Antonovsky, A., 1979: Health, Stress and Coping: New Perspectives on Mental Health and Well-Being. 1st ed. Jossey-Bass, 255 pp.

_ 1987: Unraveling the Mystery of Health. 1st ed. Jossey-Bass, 218 pp.

- 1993: The structure and properties of the sense of coherence scale. Soc. Sci. Med., 36, 725-733, https://doi.org/10.1016/ 0277-9536(93)90033-Z.

— 1996: The salutogenic model as a theory to guide health promotion. Health Promot. Int., 11, 11-18, https://doi.org/ 10.1093/heapro/11.1.11.

Arbuthnott, K. G., and S. Hajat, 2017: The health effects of hotter summers and heat waves in the population of the United Kingdom: A review of the evidence. Environ. Health, 16, 119, https://doi.org/10.1186/s12940-017-0322-5.

Bartley, M., 2006: Capability and resilience: Beating the odds. ESRC Human Capability and Resilience Research Network London and UCL Department of Epidemiology and Public Health Booklet, 24 pp., http://www.ucl.ac.uk/capabilityandresilience/ beatingtheoddsbook.pdf.

Basu, R., 2009: High ambient temperature and mortality: A review of epidemiologic studies from 2001 to 2008. Environ. Health, 8 , 40, https://doi.org/10.1186/1476-069X-8-40.

Berkes, F., and H. Ross, 2013: Community resilience: Toward an integrated approach. Soc. Nat. Resour., 26, 5-20, https:// doi.org/10.1080/08941920.2012.736605.

Borglin, G., U. Jakobsson, A. Edberg, and I. Hallberg, 2006: Older people in Sweden with various degrees of present quality of life: Their health, social support, everyday activities and sense of coherence. Health Soc. Care Community, 14, 136-146, https://doi.org/10.1111/j.1365-2524.2006.00603.x.

Braun, V., and V. Clarke, 2006: Using thematic analysis in psychology. Qual. Res. Psychol., 3, 77-101, https://doi.org/ 10.1191/1478088706qp063oa.

Brown, K., and E. Westaway, 2011: Agency, capacity, and resilience to environmental change: Lessons from human development, well-being, and disasters. Annu. Rev. Environ. Resour., 36, 321-342, https://doi.org/10.1146/annurev-environ052610-092905.

Cai, H., N. S. N. Lam, Y. Qiang, L. Zou, R. M. Correll, and V. Mihunov, 2018: A synthesis of disaster resilience measurement methods and indices. Int. J. Disaster Risk Reduct., 31, 844-855, http://doi.org/10.1016/j.ijdrr.2018.07.015.

Carvalho, A., L. Schmidt, F. Santos, and A. Delicado, 2014: Climate change research and policy in Portugal. Wiley Interdiscip. Rev.: Climate Change, 5, 199-217, https://doi.org/ 10.1002/WCC.258.

Castleden, M., M. McKee, V. Murray, and G. Leonardi, 2011: Resilience thinking in health protection. J. Public Health, 33, 369-377, https://doi.org/10.1093/pubmed/fdr027.

Clare, A., R. Graber, L. Jones, and D. Conway, 2017: Subjective measures of climate resilience: What is the added value for policy and programming? Global Environ. Change, 46, 17-22, https://doi.org/10.1016/j.gloenvcha.2017.07.001.

Committee on Climate Change, 2014: Managing climate risks to well-being and the economy. Adaptation Sub-Committee Progress Rep. 2014, 202 pp., https://www.theccc.org.uk/ publication/managing-climate-risks-to-well-being-and-theeconomy-asc-progress-report-2014/.

Conlon, K., N. Rajkovich, J. White-Newsome, L. Larsen, and M. O'Neill, 2011: Preventing cold related morbidity and mortality in a changing climate. Maturitas, 69, 197-202, https:// doi.org/10.1016/j.maturitas.2011.04.004.

Dominelli, L., 2013: Mind the gap: Built infrastructures, sustainable caring relations, and resilient communities in extreme weather events. Aust. Soc. Work, 66, 204-217, https://doi.org/10.1080/ 0312407X.2012.708764.

Drageset, J., H. Nygaard, G. Eide, M. Bondevik, M. Nortvedt, and G. Natvig, 2008: Sense of coherence as a resource in relation to health-related quality of life among mentally intact nursing home residents-A questionnaire study. Health Qual. Life Outcomes, 6, 85, https://doi.org/10.1186/1477-7525-6-85.

Engle, N., A. de Bremond, E. Malone, and R. Moss, 2013: Towards a resilience indicator framework for making climate-change adaptation decisions. Mitig. Adapt. Strategies Global Change, 19, 1295-1312, http://doi.org/10.1007/s11027-013-9475-x.

Eriksson, M., and B. Lindstrom, 2005: Validity of Antonovsky's sense of coherence scale: A systematic review. J. Epidemiol. Community Health, 59, 460-466, https://doi.org/10.1136/ jech.2003.018085. 
, and - 2008: A salutogenic interpretation of the Ottawa Charter. Health Promot. Int., 23, 190-199, https://doi.org/ 10.1093/heapro/dan014.

Folke, C., S. Carpenter, B. Walker, M. Scheffer, T. Chapin, and J. Rockstrom, 2010: Resilience thinking: Integrating resilience, adaptability and transformability. Ecol. Soc., 15, 20, https://doi.org/10.5751/ES-03610-150420.

Forbes, D., 2001: Enhancing mastery and sense of coherence: Important determinants of health in older adults. Geriatr. Nurs., 22, 29-32, https://doi.org/10.1067/mgn.2001.113532.

Glandon, D., J. Muller, and A. Almedom, 2008: Resilience in postKatrina New Orleans, Louisiana: A preliminary study. Afr. Health Sci., 8 (1), S21-S27.

Griffiths, C. A., P. Ryan, and J. H. Foster, 2011: Thematic analysis of Antonovsky's sense of coherence theory. Scand. J. Psychol., 52, 168-173, https://doi.org/10.1111/j.1467-9450.2010.00838.x.

Hahn, M., A. Riederer, and S. Foster, 2009: The livelihood vulnerability index: A pragmatic approach to assessing risks from climate variability and change-A case study in Mozambique. Global Environ. Change, 19, 74-88, https://doi.org/10.1016/ j.gloenvcha.2008.11.002.

Hajat, S., 2017: Correction to: Health effects of milder winters: A review of evidence from the United Kingdom. Environ. Health, 17, 7, https://doi.org/10.1186/s12940-018-0353-6.

_, R. Kovats, and K. Lachowycz, 2007: Heat-related and cold-related deaths in England and Wales: Who is at risk? Occup. Environ. Med., 64, 93-100, https://doi.org/10.1136/oem.2006.029017.

Hales, S., T. Blakely, R. Foster, M. Baker, and P. HowdenChapman, 2012: Seasonal patterns of mortality in relation to social factors. J. Epidemiol. Community Health, 66, 379-384, https://doi.org/10.1136/jech.2010.111864.

Hansen, A., P. Bi, M. Nitschke, D. Pisaniello, J. Newbury, and A. Kitson, 2011: Perceptions of heat susceptibility in older people: Barriers to adaptation. Int. J. Environ. Res. Public Health, 8, 4714-4728, https://doi.org/10.3390/ijerph8124714.

Haq, G., J. Whitelegg, and M. Kohler, 2008: Growing Old in a Changing Climate. Stockholm Environmental Institute, 38 pp.

Hatvani-Kovacs, G., J. Bush, E. Sharifi, and J. Boland, 2018: Policy recommendations to increase urban heat stress resilience. Urban Climate, 25, 51-63, https://doi.org/10.1016/j.uclim.2018.05.001.

IPCC, 2012: Managing the Risks of Extreme Events and Disasters to Advance Climate Change Adaptation. Cambridge University Press, 582 pp.

- 2018: Summary for policymakers. Global warming of $1.5^{\circ} \mathrm{C}$, World Meteorological Organization, 1-32, https://report.ipcc.ch/ sr15/pdf/sr15_spm_final.pdf.

Kimhi, S., 2016: Levels of resilience: Associations among individual, community and, national resilience. J. Health Psychol., 21, 164-170, http://doi.org/10.1177/1359105314524009.

_- Y. Eshel, L. Zysberg, S. Hantman, and G. Enosh, 2010: Sense of coherence and sociodemographic characteristics predicting posttraumatic stress symptoms and recovery in the aftermath of the Second Lebanon War. Anxiety Stress Coping, 23, 139-152, https://doi.org/10.1080/10615800902971513.

Kovats, R. S., R. Valentini, L. M. Bouwer, E. Georgopoulou, D. Jacob, E. Martin, M. Rounsevell, and J.-F. Soussana, 2014: Europe. Climate Change 2014: Impacts, Adaptation, and Vulnerability, Part B: Regional Aspects, V. R. Barros et al., Eds., Cambridge University Press, 1267-1326, https://www.ipcc.ch/site/assets/ uploads/2018/02/WGIIAR5-Chap23_FINAL.pdf.

Leichenko, R., 2011: Climate change and urban resilience. Curr. Opin. Environ. Sustain., 3, 164-168, https://doi.org/10.1016/ j.cosust.2010.12.014.
Lezwijn, J., J. Naaldenberg, L. Vaandrager, and C. van Woerkum, 2011: Neighbors connected: The interactive use of multi-method and interdisciplinary evidence in the development and implementation of neighbors connected. Global Health Promot. Educ., 18, 27-30, https://doi.org/10.1177/1757975910393167.

Lindstrom, B., and M. Eriksson, 2005: Salutogenesis. J. Epidemiol. Community Health, 59, 440-442, https://doi.org/10.1136/jech. 2005.034777.

— , and - 2006: Contextualizing salutogenesis and Antonovsky in public health development. Health Promot. Int., 21, 238-244, https://doi.org/10.1093/heapro/dal016.

Lorenz, D., 2013: The diversity of resilience: Contributions from a social science perspective. Nat. Hazards, 67, 7-24, https:// doi.org/10.1007/s11069-010-9654-y.

Lucio, P., A. Silva, and A. Serrano, 2010: Changes in occurrences of temperature extremes in continental Portugal: A stochastic approach. Meteor. Appl., 17, 404-418, https://doi.org/10.1002/ met.171.

Luthar, S., D. Cicchetti, and B. Becker, 2000: The construct of resilience: A critical evaluation and guidelines for future work. Child Dev., 71, 543-562, https://doi.org/10.1111/1467-8624.00164.

Martin-Breen, P., and J. M. Anderies, 2011: Resilience: A Literature Review. Rockefeller Foundation, 67 pp.

Naaldenberg, J., H. Tobi, F. van den Esker, and L. Vaandrager, 2011: Psychometric properties of the OLQ-13 scale to measure sense of coherence in a community-dwelling older population. Health Qual. Life Outcomes, 9, 37, https://doi.org/10.1186/ 1477-7525-9-37.

Nelson, D., W. Adger, and K. Brown, 2007: Adaptation to environmental change: Contributions of a resilience framework. Annu. Rev. Environ. Resour., 32, 395-419, https://doi.org/ 10.1146/annurev.energy.32.051807.090348.

Nogueira, P. J., A. R. Nunes, B. Nunes, J. M. Falcão, and P. Ferrinho, 2009: Internamentos hospitalares associados à onda de calor de Agosto de 2003: Evidências de associação entre morbilidade e a ocorrência de calor. Rev. Port. Saude Publica, 27, 87-102.

Nunes, A. R., 2018: The contribution of assets to adaptation to extreme temperatures among older adults. PLOS ONE, 13, e0208121, https://doi.org/10.1371/journal.pone.0208121.

_ 2019a: Misdiagnosing vulnerability to heatwaves in the media. Lancet Planet. Health, 3, e293, https://doi.org/10.1016/ S2542-5196(19)30107-X.

,$- 2019 \mathrm{~b}$ : General and specified vulnerability to extreme temperatures among older adults. Int. J. Environ. Health Res., 30, 515-532, http://doi.org/10.1080/09603123.2019.1609655.

— - K. Lee, and T. O'Riordan, 2016: The importance of an integrating framework for achieving the sustainable development goals: The example of health and well-being. BMJ Global Health, 1, e000068, https://doi.org/10.1136/bmjgh-2016-000068.

Pajares, F., 1996: Self-efficacy beliefs in achievement settings. Rev. Educ. Res., 66, 543-578, https://doi.org/10.3102/00346543066004543.

Preston, B., E. Yuen, and R. Westaway, 2011: Putting vulnerability to climate change on the map: A review of approaches, benefits, and risks. Sustainability Sci., 6, 177-202, https://doi.org/ 10.1007/s11625-011-0129-1.

Royal Society, 2014: Resilience to extreme weather. Royal Society Science Policy Centre Rep. 02/14, 124 pp., https:// royalsociety.org/ /media/policy/projects/resilience-climatechange/resilience-full-report.pdf.

Schneider, G., G. Driesch, A. Kruse, M. Wachter, H. Nehen, and G. Heuft, 2004: What influences self-perception of health in the elderly? The role of objective health condition, subjective 
well-being and sense of coherence. Arch. Gerontol. Geriatr., 39, 227-237, https://doi.org/10.1016/j.archger.2004.03.005.

Schwarzer, R., and M. Jerusalem, 1995: Generalized self-efficacy scale. Measures in Health Psychology: A User's Portfolio-Causal and Control Beliefs, J. Weinman, S. Wright, and M. Johnston, Eds., Windsor NFER-NELSON, 35-37.

Seidman, I., 1998: Interviewing as Qualitative Research. Teachers College Press, 209 pp.

Smith, K. R., and Coauthors, 2014: Human health: Impacts, adaptation, and co-benefits. Climate Change 2014: Impacts, Adaptation, and Vulnerability, Part A: Global and Sectoral Aspects, C. B. Field et al., Eds., Cambridge University Press, 709-754.

Sullivan, C., J. R. Meigh, and T. S. Fediw, 2002: Derivation and testing of the water poverty index phase 1, final report. Department for International Development Rep., 53 pp., http://nora.nerc.ac.uk/id/eprint/503246/1/WaterPovertyIndex_ Phase1_2002_Final\%20Report.pdf.

Tavakol, M., and R. Dennick, 2011: Making sense of Cronbach's alpha. Int. J. Med. Educ., 2, 53-55, https://doi.org/10.5116/ ijme.4dfb.8dfd.

United Nations Development Programme, 2007: Fighting climate change: Human solidarity in a divided world. UNDP Human
Development Rep. 2007/08, 399 pp., http://hdr.undp.org/en/ content/human-development-report-20078.

Vincent, K., 2004: Creating an index of social vulnerability to climate change for Africa. Tyndall Center for Climate Change Research Working Paper 56, 41 pp.

Waters, J., and W. N. Adger, 2017: Spatial, network and temporal dimensions of the determinants of adaptive capacity in poor urban areas. Global Environ. Change, 46, 42-49, https:// doi.org/10.1016/j.gloenvcha.2017.06.011.

Weber, E. U., A.-R. Blais, and N. Betz, 2002: A domain-specific risk-attitude scale: Measuring risk perceptions and risk behaviors. J. Behav. Decis. Making, 15, 263-290, https://doi.org/ 10.1002/bdm.414.

Wiesmann, U., and H. Hannich, 2010: A salutogenic analysis of healthy aging in active elderly persons. Res. Aging, 32, 349-371, https://doi.org/10.1177/0164027509356954.

Wolf, J., W. Adger, I. Lorenzoni, V. Abrahamson, and R. Raine, 2010: Social capital, individual responses to heatwaves and climate change adaptation: An empirical study of two UK cities. Global Environ. Change, 20, 44-52, https://doi.org/ 10.1016/j.gloenvcha.2009.09.004.

Zuckerman, M., 1979: Sensation Seeking: Beyond the Optimal Level of Arousal. Lawrence Erlbaum Associates, 574 pp. 